Session 3249

\title{
Do It Differently to Get a Different Outcome: Integrating Content Across Disciplines to Solve an Age-old Problem
}

\author{
Elaine L. Craft \\ Florence-Darlington Technical College
}

\begin{abstract}
Required courses in engineering technology (ET) programs other than ET courses prompt the student question, "why am I learning this?" Students often fail to make the necessary connections between disciplines that enable them to apply the knowledge appropriately in "real world" situations. How many students have taken a speech course, an English course, and a mathematics course only to find that they are unable to link their writing skills to speaking persuasively to analytical analysis and research to prepare an excellent proposal once employed?

In South Carolina a new approach to the first year of engineering technology education has been developed and implemented to help students make these important connections. This new approach is producing better results in terms of retention, graduation rates, and diversity. Implementation sites have increased graduation rates more than ten fold, students from underrepresented populations are as persistent and successful as traditional students in engineering technology, minority enrollment has increased, and employer satisfaction has reached a new high.
\end{abstract}

Using research on contextual learners, student retention, and the 21 st Century workplace, a new curriculum has been designed that focuses on an integrated, problem-based approach. Two major instructional components are completed: Technology Gateway and the first-year engineering technology core, called the ET Core. Both curriculum components model the workplace through the use of industrial-type problems in the curriculum and student and faculty teams in the classroom. The general education requirements of physics, mathematics and communications are taught concurrently with technology in the context of solving workplace-related problems. The ET Core consists of eleven courses. The Technology Gateway serves as a pre-engineering technology curriculum for slightly under-prepared students. The Technology Gateway integrates the study of mathematics, communications, and technology (three courses) around industry-type problems, providing relevant, hands-on learning experiences, and addressing career exploration. Curriculum products and evaluation data may be found at www.scate.org.

Introduction

Students often fail to make the connections among the various courses within the engineering technology curriculum. Particular difficulty arises with the general education courses of physics, mathematics, and communications (English and speech). An engineering technology instructor 
too often finds that he or she must spend time teaching mathematics or physics to enable students to have the necessary academic tools to move forward with their study of specific content in engineering technology. If one can assume that the mathematics and physics instructors have covered appropriate content and that students made acceptable grades in these pre-requisite courses, then why is the knowledge not transferring in a useful way in the new environment with engineering technology applications? Similarly, an engineering technology instructor may assign a report, presentation, or analysis to students who have acceptable grades in English or speech courses taken in previous semesters only to find that the students do not appear to know how to apply what they should have learned. For example, an essay on Shakespeare last semester often fails to translate into a well-documented and presented proposal for a solution to an industry problem. A new approach to teaching and learning has been developed to address all of these issues: building links between subjects, making learning more relevant, and increasing student retention.

SC ATE Curricula and Results

With a grant from the National Science Foundation's Advanced Technological Education (ATE) program, a unique curriculum has been developed that enables students to make the connections between academic disciplines while building teamwork and communications skills beginning their first semester. Developed by technical college faculty and published by the South Carolina Advanced Technological Education Center of Excellence (SC ATE), the new curriculum has increased student retention to $75 \%-100 \%$ from semester to semester and increased graduation rates more than 10 fold from historical rates ${ }^{i}$.

Table 1. Sample data from Florence-Darlington Technical College

\begin{tabular}{|c|c|c|}
\hline Retention rates & Fall 2003 to Spring 2004 & $75.0 \%$ (36 of 48 students) \\
\hline \multirow[t]{2}{*}{ Graduation rates } & Pre-ATE curriculum & $12.0 \%$ (statewide, $\mathrm{N}=1614$ ) \\
\hline & 1998,1999 , and 2000 cohorts & $29.2-66.0 \%$ (avg. $40.7 \%$ ) \\
\hline \multirow[t]{2}{*}{ Length-of-time to graduation } & ET students not in ATE & 2.0-7.0 years (avg. 3.2) \\
\hline & ATE students '98-00 cohorts & 2.0-2.4 years (avg. 2.3) \\
\hline \multirow[t]{2}{*}{ Diversity } & Pre-ATE curriculum & 15\% African American \\
\hline & $\begin{array}{l}2002-2003 \text { with ATE } \\
2003-2004 \text { with ATE }\end{array}$ & $\begin{array}{l}31 \% \text { African American } \\
33 \% \text { African American }\end{array}$ \\
\hline
\end{tabular}

From Fall 2002 to Spring 2003, Piedmont Technical College in Greenwood, South Carolina, another SC ATE curriculum implementation site, experienced 100\% retention of students from first to second semester (31 students). Although 100\% retention is a rare result and results vary by semester and by college, retention from semester to semester has rarely fallen below $75.0 \%$.

The curriculum reform designed and implemented by the SC ATE Center of Excellence completely re-ordered and connected physics, mathematics, communications - general education courses - to engineering technology by using problem-based learning. Industry-based problem scenarios presented in an introductory engineering technology course are used as the vehicle to connect, or integrate, the disciplines. One of the most fundamental changes with the reform is 
teaching mathematics "just-in-time" to allow a student to begin physics in the first semester. This requires a mathematics instructor to teach concepts in a very different order than outlined in mathematics textbooks and to spiral back time and again to concepts at higher and higher levels until all competencies are achieved. Another change is a re-ordering of the physics syllabus to cover electrical topics before mechanical topics so that the difficulty of the related mathematics increases more gradually throughout the SC ATE ET Core curriculum.

The final major change with the ATE approach is that content is taught from application to theory as opposed to the more traditional approach of theory to application. Students begin with a problem scenario and then determine what they know and need to know to solve the problem. Problem scenarios have multiple solutions, and students work in teams throughout the entire ET core curriculum to formulate and propose solutions to the problem. Individuals are personally accountable for discipline content knowledge and for contributions to the team solution and associated presentations. Instructors also work together as a team to coordinate instruction and to assess student projects. Teams generally meet weekly to discuss the progress of students and to plan the sequence of instruction for the coming week. Instructors are routinely in the classroom at the same time only when students are making team presentations that are jointly graded by the teaching team. Students enroll in all four ATE classes simultaneously unless exempt from a course within the ET Core because of previously earned credit. It is not essential that courses in the ET Core be scheduled in an uninterrupted block of time, but this type of scheduling helps keep students focused.

Senior projects and capstone courses often "pull it all together" for four-year college engineering or engineering technology students who persist to become seniors. For two-year technical and community college students, the time frame of opportunity for faculty to help with this process is much shorter. In addition, the two-year college student is very likely to be a contextual learner for whom relevance of study is very closely linked to retention through graduation. ${ }^{\text {ii }}$ SC ATE ET Core curriculum helps put the pieces together for beginning engineering technology students beginning with the first semester of study. The result is that student success and persistence improves, and students enter the second year of study with all prerequisite skills in place. The SC ATE curriculum approaches the education of technicians in a very different, non-traditional way and is achieving very different results. For example, the curriculum makes it possible for first-semester freshmen to begin the study of physics concurrently with the study of mathematics. Traditionally, mathematics is a pre-requisite requirement before taking physics. As an added bonus, the SC ATE curriculum inherently addresses many of the new accreditation requirements of the Technology Accrediting Commission of the Accreditation Board for Engineering and Technology (TAC of ABET) ${ }^{\mathrm{iii}}$.

As a result of the success of implementation of the SC ATE curriculum at a number of colleges in South Carolina, the Kentucky Community and Technical College System and Delmar College in Corpus Christy, Texas have both chosen to adapt and implement the SC ATE model for use with their students. In Kentucky, a five-college pilot project is in progress with plans to expand the curriculum state wide. The Kentucky model uses problem-based learning in physics integrated with developmental mathematics and English courses, computer applications, and workplace readiness skills (SCANS ${ }^{\text {iv }}$ competencies). In Texas, a college consortium lead by Del Mar has adapted the Technology Gateway for use in a process technology curriculum. SC ATE 
materials are available for preview on the Internet at www.scate.org. Classroom sets of materials and instructor training are available for purchase from the SC ATE Center of Excellence and National Resource Center for Engineering Technology Education, Florence-Darlington Technical College, P.O. Box 100548, Florence, SC 29510-0548.

Review and Recognition

The SC ATE ET Core curriculum has been the subject of two peer reviews by a team of nationally-recognized experts in discipline content areas, industry standards, and curriculum development. ${ }^{\text {v }}$ One of the reviewers, Dr. Arnold Packer of the Institute for Policy Studies at Johns Hopkins University and former Chair of the SCANS Commission, said, "The SC ATE approach will, I hope, be the future of ET education." ${ }^{\mathrm{vi}}$ In fall 2003, the SC ATE ET Core curriculum was identified as one of the top four curriculum products produced by the National Science Foundation Advanced Technological Education program. In an independent study, Western Michigan University rated curriculum products in the categories of "industry standards and practice", "real world curriculum", "workplace competencies", and "access to in-depth understanding." The SC ATE ET Core curriculum received and overall score of 4.0 on a scale of 0-4.0. In particular, the SC ATE curriculum received perfect scores of "4.0" in the areas of real world curriculum and access to in-depth understanding and scores of 3.5 in the categories of industry standards and practice and workplace competencies. ${ }^{\text {vii }}$

How the Curriculum is Designed and Taught

Problem-based learning has been used as the vehicle for content integration in a series of core courses designed to be taken by associate degree engineering technology students in their first three terms (semesters) of study. This engineering technology (ET) core integrates physics, mathematics, communications and engineering technology. In addition, SC ATE has developed a three-course pre-ET curriculum called the Technology Gateway. The Technology Gateway may be completed in a single term and also integrates mathematics, communications, and technology through problem-based learning. Problem-based learning (PBL) is an effective teaching and learning approach that allows instructors to meet educational and industry-specific objectives. Also, PBL is an effective means of incorporating workplace skills such as teaming, problem solving, and technical communications into technical courses. ${ }^{\text {vii }}$

The curriculum is designed to be taught by a team of instructors, one from each discipline, who coordinate the learning for students around solving open-ended problems based on workplace scenarios. Developing problem solutions creates a "need to know" among students. Instructors then respond by providing workshops on discipline content to equip the student to move forward with identifying possible solutions to the problems. The teaching team works together to sequence instruction as well as to grade projects and presentations but otherwise instructors teach the students in separate time frames. The most effective implementation of the SC ATE ET Core and Technology Gateway curriculum occurs when students are taught in a studio-type classroom that is set up to model a workplace and where instructors come and go as classes change rather than the other way around.

Learning to work in teams is a key skill for today's graduate. A John F. Welch, CEO of General Electric, says. "If you can't operate as a team player, no matter how valuable you've been, you really don't belong at GE." ${ }^{\text {ix }}$ In both components of the SC ATE curriculum, students are taught 
to work in industry-style teams, and these teams are responsible for formulating and presenting a solution to the various challenges set forth in problem scenarios. There are 16 problem scenarios in the ET Core curriculum to be completed over three terms of study. These 16 scenarios relate to the six major physics/technical areas (electrical, mechanical, materials, thermal, fluids, and optics) to provide students foundational technical skills that they will need in their engineering technology majors. ${ }^{\mathrm{x}}$ Students are individually accountable for discipline content knowledge and thus are assessed both as individuals and as teams. In physics, courses have a PHY prefix; in English, an ENG prefix; in mathematics, a MAT prefix; and, in engineering technology, an EGR prefix. The ET Core curriculum is taught in the semester system as follows:

Table 2. SC ATE ET Core Curriculum Course Layout

\begin{tabular}{|c|c|c|}
\hline Semester 1 & Semester 2 & Semester 3 \\
\hline MAT 181,3 credit hours & MAT 182,3 credit hours & MAT 183,3 credit hours \\
\hline $\begin{array}{l}\text { PHY } 181,3 \text { credit hours } \\
\text { ( } 5 \text { contact hours) }\end{array}$ & $\begin{array}{l}\text { PHY } 182,3 \text { credit hours } \\
\text { ( } 5 \text { contact hours })\end{array}$ & $\begin{array}{l}\text { PHY } 183,3 \text { credit hours } \\
\text { ( } 5 \text { contact hours) }\end{array}$ \\
\hline $\begin{array}{l}\text { EGR } 181,1 \text { credit hour } \\
\text { ( } 3 \text { contact hours) }\end{array}$ & $\begin{array}{l}\text { EGR } 182,1 \text { credit hour } \\
\text { ( } 3 \text { contact hours) }\end{array}$ & $\begin{array}{l}\text { EGT } 183,1 \text { credit hour } \\
\text { ( } 3 \text { contact hours) }\end{array}$ \\
\hline ENG 181,3 credit hours & ENG 182,3 credit hours & \\
\hline Total: 10 credit/ 15 contact hrs. & 10 credit/15contact hrs. & 7 credit/11 contact hrs. \\
\hline
\end{tabular}

The 181, 182, and 183 courses are taken in place of freshman English composition and speech, algebra-based college physics, and technical mathematics (content drawn from intermediate and college algebra, trigonometry, and introductory calculus). Two sample problem scenarios are included below: one from first semester and another from third semester.

Table 3. Mechanical Module \#2, Forces, Assembly Line Chute project

Your company's engineering design team is in the process of designing an automated flexible manufacturing production line. This line is to assemble four different models of radios $(\mathrm{am} / \mathrm{fm}$ stereo, am/fm/cassette, am/fm/CD, and am/fm/cassette/CD) for different supply houses. An order for a single supply house may consist of a combination of each model.

To simplify manufacturing, all models will have the same basic exterior design with the differences being only the components that are inserted into the box. At the end of the manufacturing line, several orders will be queued before packing. Multiple queues will allow for rework on a defective product. In the packing queue, the design team wishes to be able to queue up to five orders. They have decided that they will be able to direct the boxes into one of five chutes for queuing.

The design team has requested that your technician team make an oral and written report on the construction of the chute to include type of material and the slope. Your team must use the following criteria:

- The chute should be made of stainless steel or aluminum.

- The drop of the chute from the assembly line to the packing station is four meters.

- The chute must be a least five meters long for sufficient numbers to be queued.

- The final velocity of the box at the bottom of the chute should be less than two meters per second to prevent damage to the components.

- You are to build a table model prototype and extrapolate the data from this prototype to the full-scale model. 
The report should contain results based on theory and empirical data.

Table 4. Content Strands for the Assembly Line Chute Project

\begin{tabular}{|l|l|l|l|}
\hline Physics & Mathematics & Technology & Communications \\
\hline *Newton's laws of & *Similar triangles & *Prototypes & *Technical reports \\
motion & *Quadratic equations & *Free body diagrams & *Comparison and \\
*Friction & *Resolve vector & *CAD & contrast \\
*Normal Force & components & & *Oral presentations \\
*Weight & *Systems of equations & & \\
\hline
\end{tabular}

Table 5. Materials Module \#2: Mechanical Properties of Materials (Hydraulic Press)

Your company, Medallions, Inc., has been in the business of making small, "coin-size" medallions for the past 10 years. Over time, the business has grown from a small garage-sized operation to a company employing more than 150 people.

The vice president (VP) for manufacturing met with you and the other technicians to brief you on a new medallion that has been ordered and will go into prototype production within the next 60 days. This metal medallion will be three inches in diameter, which is two to three times larger than any medallion that the company now manufactures.

The VP told you and your team that there is a disassembled press in storage that could be adapted to produce the new medallion. He also told you that there is a hand sketch of the assembly for the press in the files. He asked you and your team to locate the disassembled press and make a written report with recommendations for adapting the old press for production of the prototype medallion. He also requested that you make an updated CAD drawing of the assembly.

Upon going to the storage area, you are able to locate, with the aid of the hand sketch, the hydraulic ram and all components of the frame. You are not able to locate the bolts that hold the cross member to the support frame. You notice that the cross member attached to the hydraulic ram is cracked. The rating on the hydraulic ram is $220 \mathrm{~T}$.

Table 6. Content Strands for the Hydraulic Press Project

\begin{tabular}{|l|l|l|}
\hline Physics & Mathematics & Technology \\
\hline Stress & Slope of a line & Hydraulic press \\
Strain & Limits & CAD drawings \\
Shear & Derivatives & \\
Bending & Maximum/minimum & \\
Deflection & Definite integrals & \\
Moment of inertia & Area under a curve & \\
\hline
\end{tabular}

The Technology Gateway has six scenarios covering career exploration, simple machines, basic electricity, optics, thermal, and hydraulics. The format for the problem scenarios in the Technology Gateway is similar to that used in the ET Core curriculum. The Technology Gateway was designed primarily to address weaknesses in mathematics in the slightly underprepared student seeking entry in to engineering technology. The exit competencies for the Technology Gateway, therefore, are aligned with the entrance competencies for engineering 
technology. The Technology Gateway serves as an effective on-ramp for engineering technology curricula.

Students enroll simultaneously for all three courses in the Technology Gateway (EGR 104, ENG 104, and MAT 104, each 3-credit-hour courses). Similarly, students enroll in all four courses of the ET Core curriculum in the first and second terms and the three courses of the curriculum in the third term. By the third term, English requirements have been fulfilled and the curriculum concentrates on mathematics, physics and technology while still requiring demonstration of communication skills previously mastered. To attain full-time enrollment status, students often enroll in one or more additional courses each semester while completing the ET Core.

Students completing the SC ATE ET Core curriculum have proven to be prepared to succeed in the engineering technology major of their choice. ET instructors have the joy of working with students in the second year of study who have all their pre-requisites completed and have developed problem-solving, teamwork, and communication skills.

\section{Too Good to Be True?}

The SC ATE curriculum has increased graduation rates more than ten fold, students from underrepresented populations are as persistent and successful as traditional students in engineering technology, minority enrollment has increased, and employer satisfaction has reached a new high. ${ }^{\text {xi }}$ Why, then, have all colleges not quickly adopted the SC ATE approach and implemented the Technology Gateway and ET Core curricula? There are several reasons. Implementation is challenging. Faculty and student schedules are more difficult to arrange, parttime students who enroll in fewer than three classes are difficult to accommodate, dedicated classrooms are not always available, and instructors serving on ATE Teaching Teams must give up some freedom and autonomy to work well with peers from other teaching disciplines. In addition, instructors need special training to be able to effectively deliver the curriculum. To become a successful implementation site for the SC ATE ET Core curriculum, the institution's management at every level must be willing to support the change. Cost can be a factor. Although it may initially be more expensive to implement the SC ATE curriculum than to enroll engineering technology students into existing technical or college transfer general education courses, preliminary cost/benefit analyses have shown that the savings of retaining and graduating more ET students well exceeds any costs associated with offering special sections of English, physics, and mathematics just for engineering technology students. Increased enrollment in engineering technology has resulted at SC ATE implementation sites, and the added enrollment further supports the decision to offer the curriculum. College transfer agreements may need to change. Concerns about the transferability of special ATE courses have been addressed with new articulation agreements. Students who complete ATE courses have not been shown to be at any disadvantage. Small programs are already under too much pressure for enrollment. Hanging on to current practices will never make the problem go away. The SC ATE curriculum improves retention and graduation rates. If curriculum implementation is coupled with some of SC ATE's effective recruitment strategies, enrollment may cease to be a department's greatest challenge. Employer satisfaction increases. Every employer who has had an opportunity to work with a student in the SC ATE curriculum or with a graduate of the program reports a noticeable difference. Although traditionally pleased with the technical competence of graduates, the problem-solving, teamwork, and communication skills of students 
who participate in the SC ATE curriculum sets them apart and makes them better employees. The early introduction to problem-solving and teamwork and the emphasis on communication skills in the SC ATE curriculum has prompted employers to support the program through an ATE Industry Consortium. Employers hire student in the program as early as the second semester and provide full scholarships in addition to paid internships. Information about the ATE Scholars model may be found at www.scate.org.

\section{Conclusion}

An integrated, problem-based curriculum, collaborative teaching strategies and extensive active learning techniques-together with faculty and student teams-form the cornerstone of the South Carolina Advanced Technological Education Center of Excellence's successful strategy and nationally-acclaimed model for recruiting, retaining, and graduating more students in engineering technology programs. Implementation of the SC ATE ET Core and Technology Gateway curricula is a solution that can work for others as well. The concurrent application of research-based learning theory, effective teaching methodologies, and retention strategies produces better results than any one strategy produces alone. Since the SC ATE ET Core curriculum represents a square peg to be fitted into the round hole of traditional academic settings, however, it requires organizational change. Those who adapt and implement the curriculum will find it well worth the effort to help instructors, departments, and perhaps entire institutions overcome resistance to change and the inherent difficulties of initiating a very different, but effective, model of teaching and learning to better serve their students and employers. For those who are truly ready to get different results, this is a model to consider. Perhaps most important, getting a different result — increasing the quantity, quality, and diversity of engineering technology graduates - is a goal that must be achieved to keep United States employers competitive in the global economy. ${ }^{\text {xii }}$

\section{Bibliography}

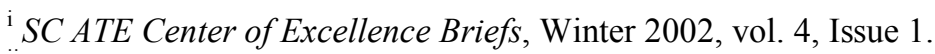

${ }^{\text {ii }}$ Monograph: Recruitment \& Retention of Engineering Technology Students (2000), South Carolina Advanced Technological Education Center of Excellence, South Carolina Technical College System.

iii SC ATE Center of Excellence Briefs, Spring 2000, vol 2, Issue 3.

iv The Secretary's Commission on Achieving Necessary Skills (SCANS), SCANS 2000: The Workforce Skills Website, Institute for Policy Studies, Johns Hopkins University, www.scans2000.jhu.edu.

${ }^{\vee}$ Peer Review '01, Evaluation, SC ATE Center of Excellence, www.scate.org.

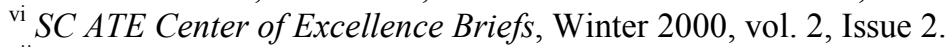

${ }^{\text {vii }}$ Letter to Elaine Craft from Evaluation Center, Western Michigan University, September 23, 2003. Results of study to be published in 2004.

viii Using Problem-based Learning to Modify Curriculum to Meet Industry Needs, James C. Wood, Proceedings of the 2002 American Society for Engineering Education Annual Conference and Exposition.

${ }^{\text {ix }}$ Teams in Engineering Education, L. Bellamy et al., Arizona State University, March 1994.

${ }^{x}$ Ibid.

${ }^{x i}$ Reforming Engineering Technology Education: Sixth Year Evaluation of South Carolina Advanced Technological Education Center of Excellence, Academy for Educational Development, Washington, DC, August 2002.

${ }^{x i i}$ Gaining the Competitive Edge: Critical Issues in Science and Engineering Technician Education, pg. v, National Science Foundation, July 1993. 
ELAINE L. CRAFT is Director of the SC ATE Center of Excellence and National Resource Center for Engineering Technology Education with offices at Florence-Darlington Technical College, P.O. box 100548, Florence, SC 29501. She holds a bachelors degree in chemical engineering and masters degree in business administration. 